\title{
Aberrant production of soluble inducible T-cell co-stimulator (sICOS) and soluble programmed cell death protein 1 (sPD-1) in patients with chronic hepatitis $\mathbf{C}$
}

\author{
DONGSHENG WANG $^{1 *}$, DING'AN ZHOU ${ }^{2 *}$, QIN DU $^{1}$, QI LIANG $^{1}$, QIANG WANG $^{1}$, LI FANG $^{1}$, \\ GUANGRONG WANG ${ }^{1}$, QUMING FAN ${ }^{1}$, BEIZHONG LIU ${ }^{3}$, JINGGUO ZHOU ${ }^{1}$, ZHONG \\ TANG $^{1}, \mathrm{HAO}^{\mathrm{W}}{ }^{4}$, XIAOLAN GUO ${ }^{1}$, YANMEI JIAO ${ }^{4}$ and GUOYUAN ZHANG ${ }^{1}$
}

\author{
${ }^{1}$ Department of Laboratory Medicine, The Affiliated Hospital of North Sichuan Medical College, Sichuan 637000; \\ ${ }^{2}$ Institutes of Biomedical Sciences, Fudan University, Shanghai 200032; ${ }^{3}$ Medical Laboratory Center of Yongchuan Hospital, \\ Chongqing Medical University, Chongqing 402160; ${ }^{4}$ Center for Infectious Diseases, Beijing You'an Hospital, \\ Capital Medical University, Beijng 100069, P.R. China
}

Received December 3, 2012; Accepted January 16, 2013

DOI: $10.3892 / \mathrm{mmr} .2013 .1326$

\begin{abstract}
Previous studies have indicated that immune dysregulation is an important cause of $\mathrm{HCV}$-mediated damage to the liver. Co-stimulation signals, including programmed cell death protein 1 (PD-1) and inducible T-cell co-stimulator (ICOS), have been demonstrated to be involved in the pathogenesis of $\mathrm{HCV}$. The purpose of this study was to investigate the soluble PD-1 (sPD-1) and soluble ICOS (sICOS) serum levels in chronic HCV patients, and to elucidate the association of sPD-1 and sICOS levels with pathological injury of chronic $\mathrm{HCV}$ infection. Sixty-three patients with chronic HCV and 30 normal controls were recruited for this study. The serum concentration levels of sPD-1 and sICOS were measured by enzyme-linked immunosorbent assay, and the mRNA levels of PD-1 and ICOS were detected using real-time RT-PCR. The serum SPD-1 and sICOS levels were significantly elevated in the chronic HCV patient group compared with the normal control group. Furthermore, the relative mRNA expression levels of these proteins were also increased in chronic HCV patients. sPD-1 and sICOS serum levels were significantly correlated with anti-HCV antibody levels, but not with HCV
\end{abstract}

Correspondence to: Yanmei Jiao, Center for Infectious Diseases, Beijing You'an Hospital, Capital Medical University, No. 10 Xitoutiao, Beijng 100069, P.R. China

E-mail: jiaoyanmei@gmail.com

Guoyuan Zhang, Department of Laboratory Medicine, The Affiliated Hospital of North Sichuan Medical College, 63 Wenhua Road, Nanchong 637000, P.R. China

E-mail: zhangguoyuan9826@126.com

*Contributed equally

Key words: co-stimulatory molecules, sICOS, sPD-1, dysregulation of T-cell activation, chronic hepatitis $\mathrm{C}$
RNA. Aberrant SPD-1 and sICOS serum levels may reflect the dysregulation of T-cell activation, and are associated with the pathological injury of chronic HCV infection.

\section{Introduction}

Almost 3\% of the world's population is infected with hepatitis $\mathrm{C}$ virus (HCV) (1). Chronic infection with HCV may result in both hepatic and extrahepatic disease, such as inflammation of the liver, which in turn may progress to cirrhosis, liver failure or cancer (2). The mechanism whereby $\mathrm{HCV}$ damages the liver is unclear, but there is much evidence to suggest that the immunity disorder is one of the important reasons for this (3). Active $\mathrm{T}$ cells in the liver may target those hepatocytes infected with $\mathrm{HCV}$ and clear them to prevent virus prevalence. Once infected with $\mathrm{HCV}$, the $\mathrm{HCV}$ particles are processed by antigen-presenting cells (APC) and then presented to naive $\mathrm{T}$ cells by major histocompatibility complex (MHC) molecules, which deliver a primary signal to initiate T-cell activation by the engagement of the T-cell receptor/CD3 complex with foreign antigens associated with MHC. In addition, the optimal activation of $\mathrm{T}$ cells requires a co-stimulatory signal. Co-stimulatory signals include CD28/ B7 and TNFR/TNF superfamilies; however, numerous novel molecules, such as programmed death 1 (PD-1), inducible T-cell co-stimulator (ICOS), B and T lymphocyte attenuator (BTLA), B7-H1 (PD-L1), B7RP-1 (B7H,B7-H2), B7-DC (PD-L2), B7-H3 and B7-H4, have recently been identified (4). These signals are also important in physiological functions and pathologic progress (4). Cytotoxic T lymphocytes (CTL) are hypothesized to control HCV replication, but these fail in numerous persistently infected individuals (5-7). Additionally, the CTL numbers are often low in chronic HCV patients, as the $\mathrm{HCV}$ core protein is able to suppress the host immune response (8-11). Monocyte-derived dendritic cells (Mo-DCs) generated from hepatitis $\mathrm{C}$ patients have an impaired ability to stimulate allogeneic $\mathrm{CD} 4^{+} \mathrm{T}$ cells that are not able to release a significant amount of effective cytokines (12). However, 
the exact immunopathological mechanisms by which $\mathrm{HCV}$ escapes the host immune response remain unknown.

Previous studies have demonstrated that co-stimulators, PD-1 and ICOS, are involved in the HCV pathogenic progress. PD-1 receptor expression is greater in dysfunctional HCV-specific T cells compared with normal cells $(13,14)$. In acute $\mathrm{HCV}$ affections, PD-1 also upregulates $\mathrm{CD}^{+}$and $\mathrm{CD} 8^{+}$ $\mathrm{T}$ lymphocytes. Interaction with its ligand, PD-L1, in the $\mathrm{HCV}$-specific $\mathrm{T}$ cells inhibits effector functions and induces T-cell apoptosis. In an $\mathrm{HCV}$ core(+) mouse model, $\mathrm{CD}^{+}$cells were accompanied with enhanced PD-1 expression. The core antigen of $\mathrm{HCV}$ is an immunomodulatory protein that alters the adaptive immune response (11). The aforementioned findings demonstrate that PD-1 is randomly expressed in $\mathrm{HCV}$-specific immune cells, although its function has not yet been fully elucidated.

Another co-stimulator, ICOS, also assists in activating adaptive immunity, particularly by aiding antibody secretion by B cells. However, there is limited number of studies concerning ICOS in HCV patients. Ribavirin downmodulates ICOS in $\mathrm{CD}^{+}{ }^{+} \mathrm{T}$ cells and assists $\mathrm{HCV}$ clearance, indicating that ICOS prevention is a novel choice for HCV treatment (15). In addition, ICOS has been found to be upregulated in chronic HBV-infected cells.

Previous studies have demonstrated that there are different isoforms of PD-1 and ICOS from alternatively spliced messenger RNA (mRNA), and the soluble isoforms of these may regulate immune homeostasis (16). In addition, soluble ICOS (sICOS) and soluble PD-1 (sPD-1) have been identified to be present in numerous diseases, particularly autoimmune diseases, such as systemic lupus erythematosus (SLE) and cancer. However, the clinical significance of these markers in chronic HCV infection remains uncertain. The aim of this study was to elucidate the correlation between these soluble molecules and T-cell activation in chronic HCV patients, and to investigate their possible association with the pathogenesis of $\mathrm{HCV}$.

\section{Materials and methods}

Subjects. Sixty-three Chinese patients with chronic HCV and 30 volunteers (normal controls) were recruited in this study. The individuals with chronic HCV were patients at The Affiliated Hospital of North Sichuan Medical College and the Yongchuan Hospital of Chongqing Medical University. All patients were anti-HCV antibody- and HCV RNA-positive, but negative for HBV, HDV and human immunodeficiency virus, and without any other disease-related liver damage. Patients with concomitant illness and autoimmune disease were excluded. No patients had accepted administration of anti-HCV agents or steroids one year prior to sampling. Each individual signed the written informed consent, and the protocol was approved by the Clinical Research Ethics Committee of the affiliated hospital of North Sichuan Medical College.

Virological detection and biochemistry assays. Anti-HCV antibody was determined by a kit (i2000; Abbort, Wiesbaden, Germany). The HCV RNA level was determined by real-time RT-PCR using the LightCycler ${ }^{\circledR} 480$ System (Roche Diagnostics $\mathrm{GmbH}$, Mannheim, Germany) with a detection sensitivity of
$1 \times 10^{3} \mathrm{IU} / \mathrm{ml}$. Serum alanine aminotransferase (ALT), aspartate aminotransferase (AST), total bilirubin (TB) and direct bilirubin (DB) were measured by the Synchron LX20 auto-analyzer (Beckman Coulter Inc., Fullerton, CA, USA).

ELISA assay of SICOS and SPD-1. Serum concentrations of sICOS and SPD-1 of all patients and the normal control group were detected with ELISA (R\&D Systems, Inc., Minneapolis, MN, USA). The assay was conducted according to the manufacturer's instructions.

Real-time RT-PCR. Peripheral blood mononuclear cells (PBMC) were obtained according to the specification of the kit (Tianjin Hao Yang Biological Manufacture Co., Ltd., Tianjin, China). RNA extraction and cDNA synthesis were performed according to the experimental guidelines of Promega Corporation (Madison, WI, USA). The PCR primer sequences used were: Sense 5'-GTTCCCTGAGTTGTTTG-3' and antisense: 5'-TCATCTTGAGGTGTCCC-3' for ICOS; sense 5'-CCGCCTTCTGTAATGGTTTGA-3' and antisense: 5'-GGGCAGCTGTATGATCTGGAA-3' for PD-1 (17). GAPDH was used as an internal control. Relative quantification was calculated using the $2^{-\Delta \Delta C t}$ formula.

Statistical analysis. The Mann-Whitney rank sum test was used to analyze the difference in SPD-1 and sICOS levels between normal controls and patients. The Spearman's rank correlation test was used to assess the correlation between SPD-1, sICOS and ALT or anti-HCV antibody levels. Results are expressed as the median (interquartile range). The data were analyzed with OriginPro 8.5 statistical software. $\mathrm{P}<0.05$ was considered to indicate a statistically significant difference.

\section{Results}

Numerous biochemical marker levels were increased in chronic HCV patients compared with the normal controls. Sixty-three patients with chronic HCV infection and 30 normal controls were studied. The detection results of ALT, AST, DB and TB are summarized in Table I. Serum AST, ALT, TB and DB were significantly elevated in the HCV group compared with the normal control group, indicating that HCV chronic infection causes liver damage.

Serum levels of SPD-1 and SICOS were elevated in chronic HCV patients compared with the normal controls. The sPD-1 and sICOS serum levels were extremely low in the normal controls, a large number of which were below the detection limit of the two kits (Fig. 1A and B, respectively). However, the sPD-1 and sICOS levels were significantly higher in patients with chronic $\mathrm{HCV}$ infection compared with the normal controls ( $\mathrm{P}<0.01$ for both; Fig. 1A and B, respectively).

SPD-1 and sICOS are correlated with anti-HCV antibodylevels in chronic HCV patients. A potential correlation was identified between serum ALT and SPD-1/sICOS. A significant correlation between ALT and sPD-1 levels was observed $(r=0.268$, $\mathrm{P}=0.033$; Fig. 2F), although sICOS levels did not correlate with ALT levels (Fig. 2E). sPD-1 levels did not correlate with the DB and TB levels (Fig. 2A and B, respectively), whereas the sICOS 
Table I. Comparison of multiple biochemical and immunological markers between normal controls and chronic HCV patients.

Characteristic

Age (mean $\pm \mathrm{SD}$, years)

Female/male

ALT [median (IQ range), U/ml]

AST [median (IQ range), $\mathrm{U} / \mathrm{ml}$ ]

TB [median (IQ range), $\mu \mathrm{mol} / \mathrm{l}]$

$\mathrm{DB}$ [median (IQ range), $\mu \mathrm{mol} / \mathrm{l}]$

Anti-HCV [median (IQ range)]

HCV RNA $\log 10($ mean \pm SD, U/ml)

Autoimmune diseases
Normal controls $(n=30)$

Chronic hepatitis $C(n=63)$
$48 \pm 15.7$

$24 / 39$

$37(6.9-285.1)^{\mathrm{a}}$

$36.5(11.7-187)^{\mathrm{a}}$

$12.5(2.8-80.6)$

$3.7(1.1-46.8)$

$3.7(3.1-19.62)^{\mathrm{a}}$

$6.01 \pm 1.62^{\mathrm{a}}$

None

HCV, hepatitis C virus; SD, standard deviation; IQ, interquartile; ALT, alanine aminotransferase; AST, aspartate aminotransferase; TB, total bilirubin; DB, direct bilirubin; n, number of individuals. ${ }^{\mathrm{a}} \mathrm{P}<0.05$ when compared with healthy controls.

levels correlated with DB and TB levels (Fig. 2C and D, respectively), this correlation may have been due to the detection bias. However, the upregulation of DB may have been as a result of other factors. SPD-1 and sICOS serum levels correlated with anti-HCV antibody levels (sPD-1, $\mathrm{r}=0.344, \mathrm{P}=0.005$; sICOS, $\mathrm{r}=0.322, \mathrm{P}=0.009$; Fig. $3 \mathrm{~A}$ and $\mathrm{B}$, respectively), indicating that their infection may be an immune reaction in chronic $\mathrm{HCV}$ patients. However, no difference in sICOS or sPD-1 levels between $\mathrm{HCV}$ patients with normal and abnormal ALT results was detected (F sig. 4A and B, respectively).

No correlation was evident between HCV RNA levels and $s P D-1 / s I C O S$ concentration. HCV RNA levels were measured using real-time RT-PCR and the statistical analysis revealed that there was no significant correlation between HCV RNA levels and sICOS $(\mathrm{P}>0.05)$ or SPD-1 ( $>>0.05)$ levels in patients with chronic $\mathrm{HCV}$ infection (Fig. $4 \mathrm{~A}$ and $\mathrm{B}$, respectively). In addition, the correlation between SPD-1 and sICOS levels was not significant (Fig. 5).

PD-1 and ICOS mRNA levels were elevated in PBMC of HCV patients. Quantitative RT-PCR demonstrated that the mRNA levels of PD-1 and ICOS in PBMC were elevated in chronic $\mathrm{HCV}$ patients compared with the normal controls (Fig. 6A and $\mathrm{B}$, respectively). Considering that SPD-1 and sICOS may be shed from the membrane of these cells, the upregulation of these molecules may be one of the reasons to explain the high levels of PD-1 and ICOS in HCV patients.

\section{Discussion}

Communication between $\mathrm{T}$ cells and APC initiates the immune response to $\mathrm{HCV}$ infection. Dysfunction of $\mathrm{T}$ cells and abnormal immunomodulation molecules of APC in HCV patients have been demonstrated $(18,19)$. However, the soluble co-stimulatory molecules in chronic $\mathrm{HCV}$ patients has not previously been investigated.

In the present study, we demonstrated that the serum concentrations of SPD-1 and sICOS were markedly elevated in chronic $\mathrm{HCV}$ patients compared with the normal controls. The levels of sPD-1 and sICOS were significantly correlated
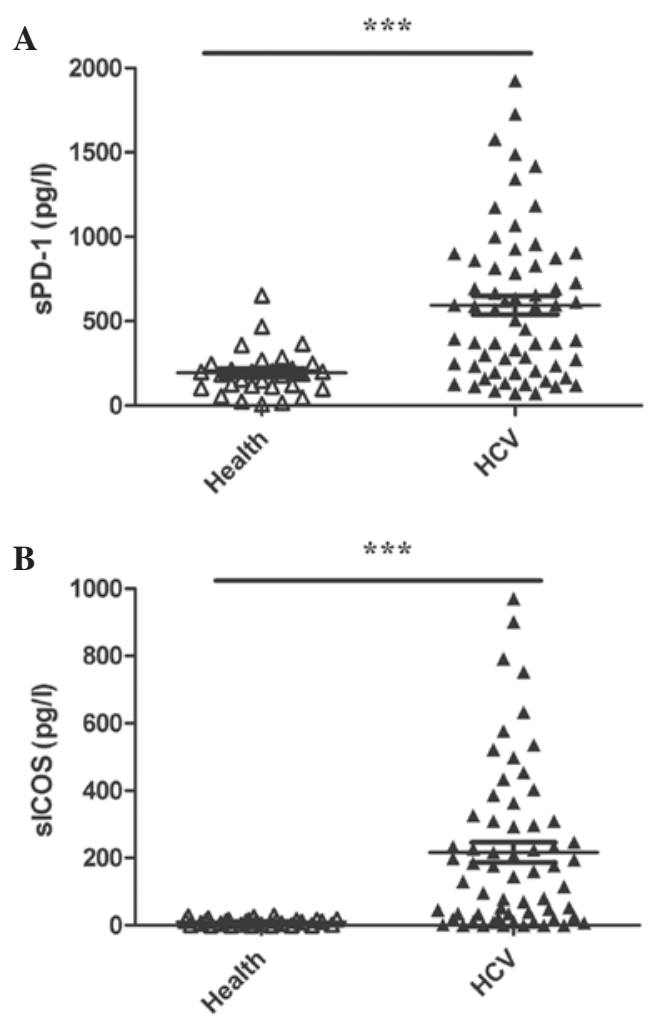

Figure 1. Soluble programmed cell death protein 1 (sPD-1) and soluble inducible T-cell co-stimulator (sICOS) serum levels are significantly higher in patients with chronic hepatitis $\mathrm{C}$ virus (HCV) infection compared with the normal controls. ${ }^{* * *} \mathrm{P}<0.01$. HCV, chronic HCV-infected patients; health, normal controls.

with the anti-HCV antibody serum levels in HCV patients. The anti-HCV antibody levels are recognized as HCV infection markers, and high anti-HCV antibody levels indicate active replication of HCV. However, in the present study, the sPD-1 and sICOS levels were not significantly correlated with the HCV RNA level. This may be due to the fact that the immune regulation ability of PD-1 and ICOS is not very effective at influencing the virus replication; thus, they are not sensitively reactive to the changes in HCV RNA levels. There are numerous co-stimulatory molecules, such as CD28, CD80, 
A

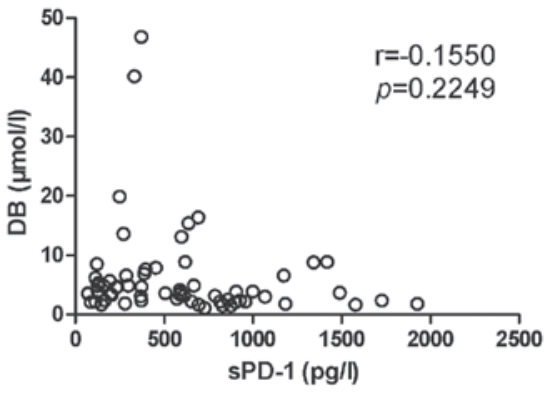

C

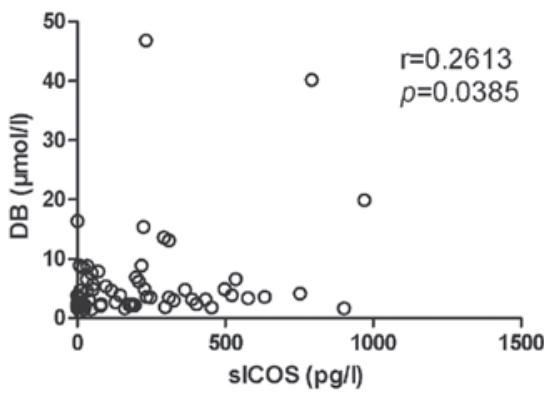

$\mathbf{E}$

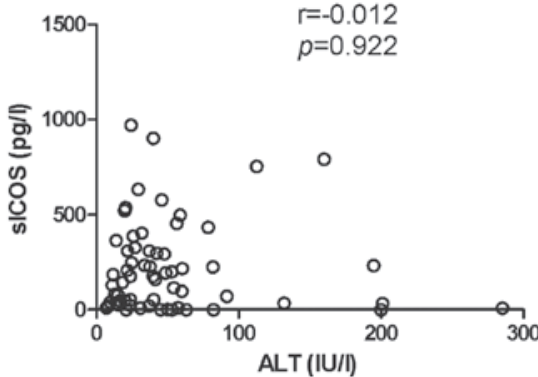

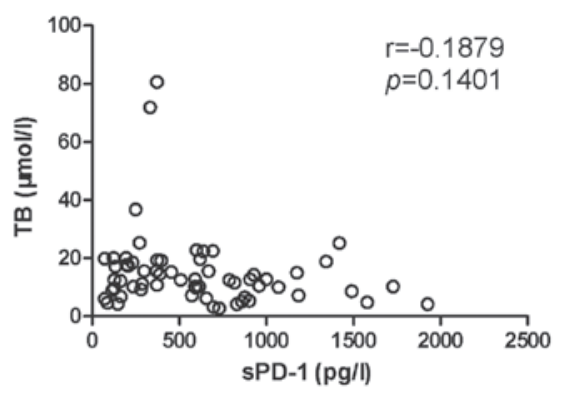

D
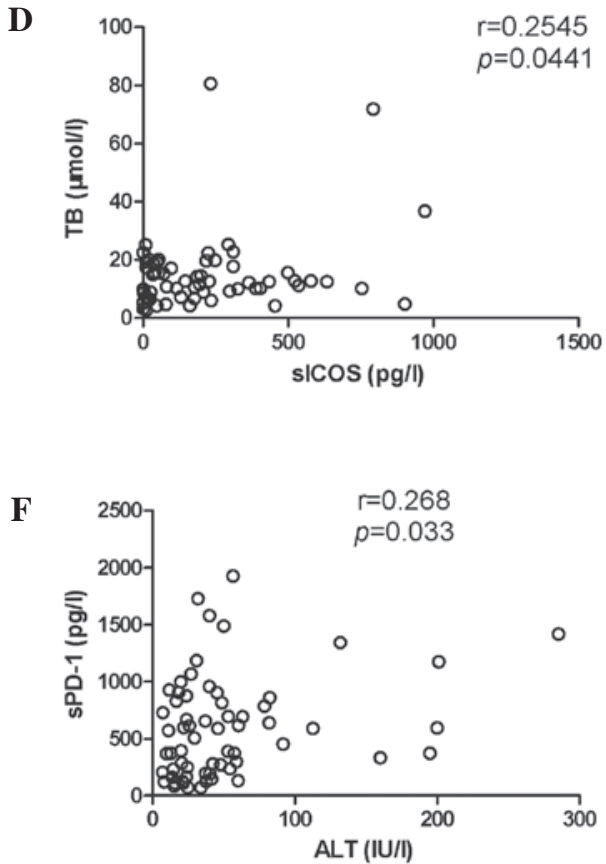

Figure 2. Correlation analyses of soluble programmed cell death protein 1 (sPD-1) and soluble inducible T-cell co-stimulator (sICOS) with total bilirubin (TB), direct bilirubin (DB), alanine aminotransferase (ALT) and anti-hepatitis C virus (HCV) antibody in chronic HCV patients. sPD-1 levels did not correlate with (A) DB or (B) TB levels. sICOS levels correlated with (C) DB and (D) TB levels. sICOS levels did not correlate with (E) ALT levels, whereas, sPD-1 levels correlated with (F) ALT levels.

CD86 and CTLA, all of which have two forms (the membrane and soluble forms) (20). sPD-1 and sICOS are formed from alternative mRNA splicing. Since sPD-1, and not sICOS, has been demonstrated to be highly expressed in the active lymphocytes of autoimmune diseases (21), sPD-1 may not be a specific molecule in chronic HCV infection. Additionally, sICOS has not been investigated previously. Therefore, these two markers are not necessarily disease-specific molecules. However, due to their correlation with the anti-HCV antibody, sPD-1 and sICOS may be partially associated with virus replication and $\mathrm{HCV}$ pathogenesis, which may lead to the dysregulation of T-cell co-stimulation.

In the present study, we found that the SPD-1 and sICOS levels were significantly higher in the HCV group compared with the normal control group. However, the biological significance of these results remains unknown. Both of these molecules have an immunomodulatory function. Increased production of sPD-1 and sICOS may interfere with the patient's adaptive immune function. sPD-1 and sICOS may compete and interfere with the PD-1 and ICOS interactions with their respective ligands, leading to immune dysregulation and a defective immune response. PD-1/PD-L has been demonstrated to negatively regulate the T-cell response, both in the primary and secondary immune responses (22). Blocking the PD-1/ PD-L pathway could enhance the anti-virus immunity. Thus, the abnormal expression of sPD-1 may interact with PD-L and inhibit PD-1/PD-L axis-induced T-cell apoptosis, leading to continuation of T-cell activation and causing inflammation. ICOS is usually expressed in activated T cells and amplifies the first stimulator signal. Abnormal sICOS is likely to compete with ICOS-L and reduce T-cell reaction, which may cause T-cell exhausion. Both PD-1 and ICOS activation have been demonstrated to induce Th2 cytokine release and in turn suppress Th1 inflammation, leading to liver damage (23). Humoral immune function may also be enhanced by ICOS. ICOS knockout may prevent $\mathrm{T}$ cell-specific germinal center formation, as B cells have been observed to be inactive and incapable of migrating to form the germinal center. The T cells specifically induced immunoglobulin dyspoiesis, indicating that high antibody production is ICOS-dependent (24). In the present study, the high levels of sICOS were concordant with the high levels of anti-HCV antibody, which is explained by the fact that sICOS is predominantly shed from the active T-cell membranes. Thus, the aberrant production of sPD-1 
A

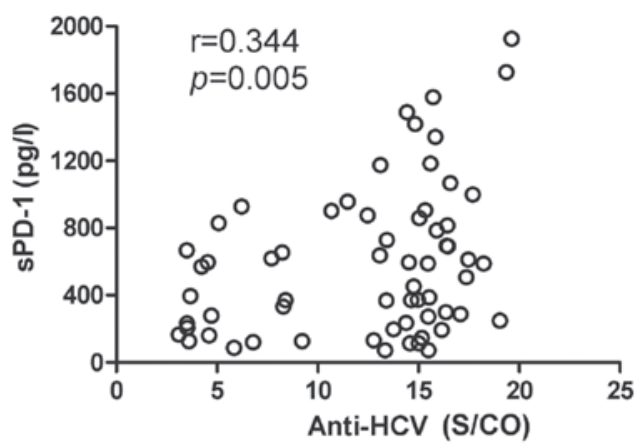

B

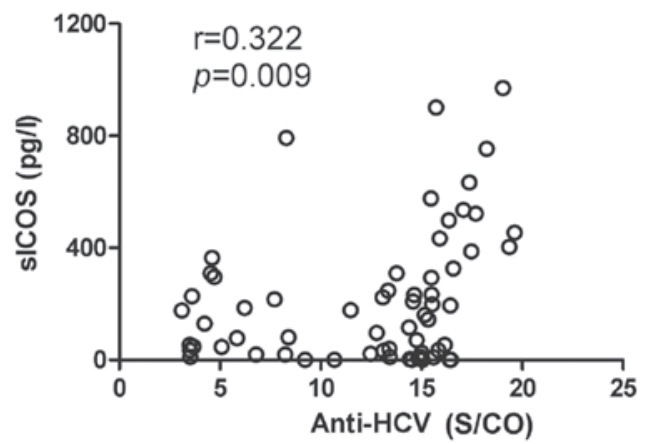

Figure 3. Analyses reveal that (A) soluble programmed cell death protein 1 (sPD-1) and (B) soluble inducible T-cell co-stimulator (sICOS) serum levels are significantly correlated with anti-hepatitis $\mathrm{C}$ virus (HCV) antibody levels in chronic HCV patients. No difference is evident in the levels of sPD-1 or sICOS between HCV patients with normal and abnormal ALT level results.

A

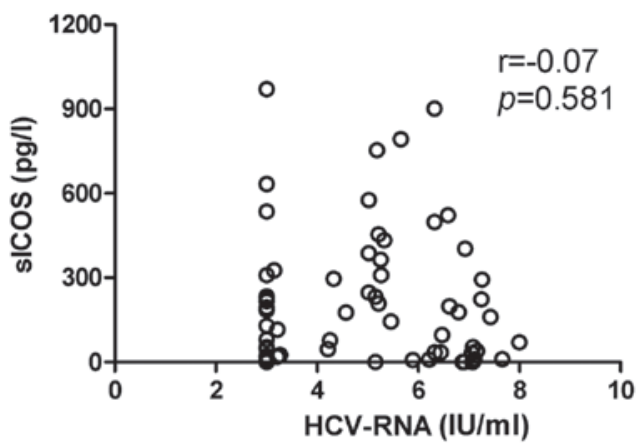

B

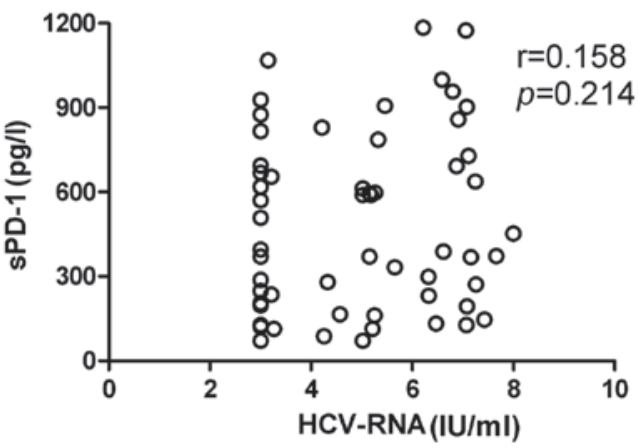

Figure 4. No correlation is evident between hepatitis C virus (HCV) RNA levels and (A) soluble inducible T-cell co-stimulator (sICOS) or (B) soluble programmed cell death protein 1 (sPD-1) levels in patients with chronic $\mathrm{HCV}$ infection.

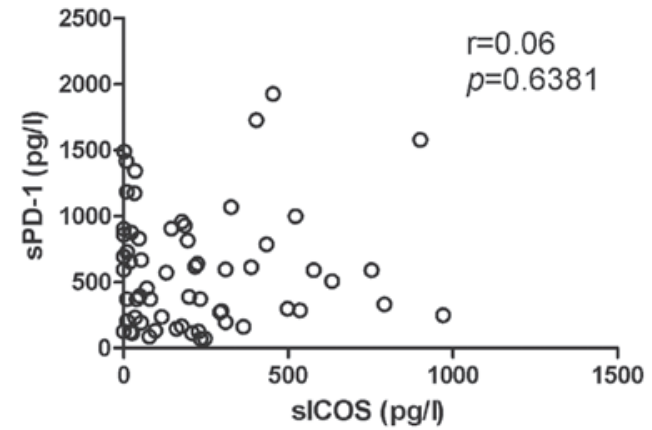

Figure 5. There is no correlation between soluble programmed cell death protein 1 (sPD-1) and soluble inducible T-cell co-stimulator (sICOS) levels in chronic HCV patients.

A

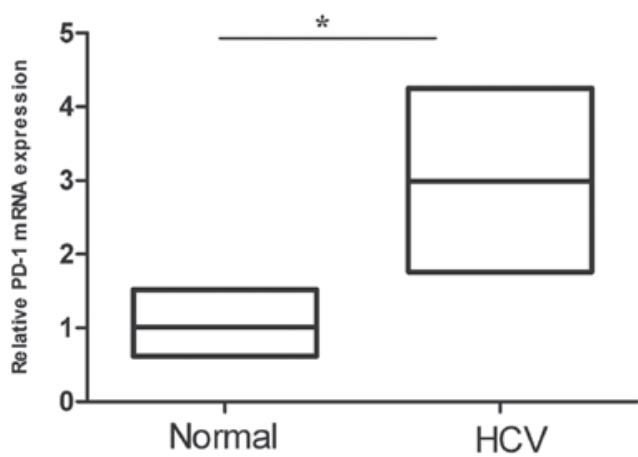

B

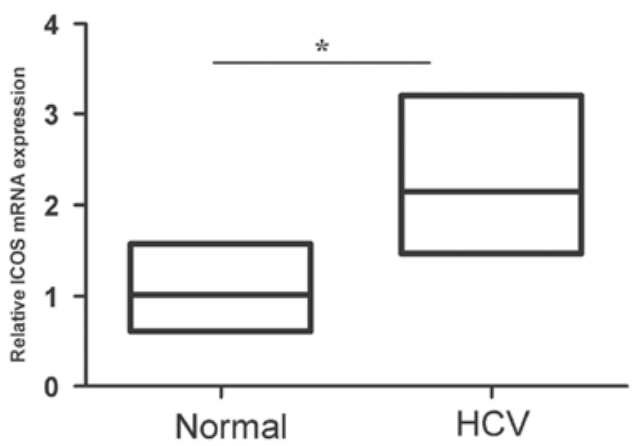

Figure 6. Quantitative RT-PCR revealed that the mRNA levels of (A) programmed cell death protein 1 (PD-1) and (B) inducible T-cell co-stimulator (ICOS) in the PBMC of chronic HCV patients are significantly higher compared with those of the normal controls, ${ }^{*} \mathrm{P}<0.01$.

and sICOS may be important in HCV infection. The detailed immunopathological roles of those soluble co-stimulatory molecules in $\mathrm{HCV}$ infection require further study.

PD-1 expression levels in $\mathrm{HCV}$-specific $\mathrm{CD}^{+}$and $\mathrm{CD} 4^{+}$ $T$ cells do not correlate with clinical outcomes (13). In addition, SPD-1 is upregulated in certain autoimmune diseases. Notably, $\mathrm{HCV}$ has recently been classified as an autoimmune disease. In the present study, TB and DB were weakly correlated with sPD-1, but not with sICOS. Similarly, ALT was correlated with sPD-1 and not with sICOS. We suggest that SPD-1 and sICOS are not disease-specific indicators, due to their weak immunomodulatory ability and the fact that their levels do not change synchronously with other biochemical markers. sPD-1 and sICOS are usually aberrant in immune disorder disease; however, they may have little correlation with the changes in liver function (Fig. 4). 
To elucidate the mechanism of soluble SPD-1 and sICOS generation, we detected the transcription level changes of the two molecules. As expected, PD-1 and ICOS levels are both higher in the HCV patient group compared with the normal control group. As the sPD-1 and sICOS mRNA levels corresponded with their membrane protein forms, the high ICOS and PD-1 mRNA levels may indicate that their soluble forms predominantly shed from the membrane, and may have a negative regulation of their function. Although the exact mechanism of the soluble forms in immune regulation is not yet clear, the different concentrations of soluble forms may have different functions in $\mathrm{HCV}$-infected patients. Blocking PD-1/PD-L has been demonstrated to be a useful way of recovering T-cell function. T cells proliferate significantly following blocking of PD-1 (25). However, in our study, upregulation of sPD-1 did not induce T-cell proliferation and clearing of the virus. Thus, T-cell function and subtype in the HCV patients should be identified, and the different concentrations and functions of sPD-1 in the T cells from HCV patients should be investigated. No studies are available regarding the manner in which sICOS affects T-cell immunity and whether it functions as a competitor of ICOS, both of which require further study.

In summary, this is the first study to identify soluble co-stimulatory molecules in chronic HCV patients. Our results provide a new direction and experimental basis to elucidate the pathological mechanism of chronic HCV infection. The soluble co-stimulatory molecules may be a new therapeutic target in HCV therapy. The biological function of SPD-1 and sICOS in HCV infection requires further study in order for their therapeutic function to be investigated.

\section{References}

1. Sorrell MF, Belongia EA, Costa J, Gareen IF, Grem JL, Inadomi JM, Kern ER, McHugh JA, Petersen GM, Rein MF, et al: National Institutes of Health consensus development conference statement: management of hepatitis B. Hepatology 49: S4-S12, 2009.

2. Rodriguez-Luna $\mathrm{H}$ and Vargas HE: Management of hepatitis $\mathrm{C}$ virus infection in the setting of liver transplantation. Liver Transpl 11: 479-489, 2005.

3. Mengshol JA, Golden-Mason L and Rosen HR: Mechanisms of Disease: HCV-induced liver injury. Nat Clin Pract Gastroenterol Hepatol 4: 622-634, 2007.

4. Sharpe AH and Freeman GJ: The B7-CD28 superfamily. Nat Rev Immunol 2: 116-126, 2002.

5. Cooper S, Erickson AL, Adams EJ, Kansopon J, Weiner AJ, Chien DY, Houghton M, Parham P and Walker CM: Analysis of a successful immune response against hepatitis $\mathrm{C}$ virus. Immunity 10: 439-449, 1999.

6. Thimme R, Oldach D, Chang KM, Steiger C, Ray SC and Chisari FV: Determinants of viral clearance and persistence during acute hepatitis C virus infection. J Exp Med 194: 1395-1406, 2001.

7. Puig M, Mihalik K, Tilton JC, Williams O, Merchlinsky M, Connors M, Feinstone SM and Major ME: $\mathrm{CD}^{+}$immune escape and subsequent T-cell failure following chimpanzee immunization against hepatitis $C$ virus. Hepatology 44: 736-745, 2006.

8. Rehermann B, Chang KM, McHutchinson J, Kokka R, Houghton M, Rice CM and Chisari FV: Differential cytotoxic T-lymphocyte responsiveness to the hepatitis $\mathrm{B}$ and $\mathrm{C}$ viruses in chronically infected patients. J Virol 70: 7092-7102, 1996.
9. Nelson DR, Marousis CG, Davis GL, Rice CM, Wong J, Houghton M and Lau JY: The role of hepatitis C virus-specific cytotoxic T lymphocytes in chronic hepatitis C. J Immunol 158: 1473-1481, 1997.

10. Cabrera R, Tu Z, Xu Y, Firpi RJ, Rosen HR, Liu C and Nelson DR: An immunomodulatory role for CD4(+)CD25(+) regulatory T lymphocytes in hepatitis $C$ virus infection. Hepatology 40 : 1062-1071, 2004.

11. Yao ZQ, King E, Prayther D, Yin D and Moorman J: T cell dysfunction by hepatitis $\mathrm{C}$ virus core protein involves PD-1/ PDL-1 signaling. Viral Immunol 20: 276-287, 2007.

12. Li S, Roberts S, Plebanski M, Gouillou M, Spelman T, Latour P, Jackson D, Brown L, Sparrow RL, Prince HM, et al: Induction of multi-functional $\mathrm{T}$ cells in a phase I clinical trial of dendritic cell immunotherapy in hepatitis C virus infected individuals. PLoS One 7: e39368, 2012.

13. Kasprowicz V, Schulze Zur Wiesch J, Kuntzen T, Nolan BE, Longworth S, Berical A, Blum J, McMahon C, Reyor LL, Elias N, et al: High level of PD-1 expression on hepatitis $\mathrm{C}$ virus $(\mathrm{HCV})$-specific $\mathrm{CD} 8^{+}$and $\mathrm{CD} 4^{+} \mathrm{T}$ cells during acute $\mathrm{HCV}$ infection, irrespective of clinical outcome. J Virol 82: 3154-3160, 2008.

14. Rutebemberwa A, Ray SC, Astemborski J, Levine J, Liu L, Dowd KA, Clute S, Wang C, Korman A, Sette A, et al: High-programmed death-1 levels on hepatitis C virus-specific $\mathrm{T}$ cells during acute infection are associated with viral persistence and require preservation of cognate antigen during chronic infection. J Immunol 181: 8215-8225, 2008.

15. Atsukawa M, Nakatsuka K, Kobayashi T, Shimizu M, Tamura H, Harimoto H, Takahashi H and Sakamoto C: Ribavirin downmodulates inducible costimulator on $\mathrm{CD} 4^{+} \mathrm{T}$ cells and their interleukin-10 secretion to assist in hepatitis $\mathrm{C}$ virus clearance. J Gastroenterol Hepatol 27: 823-831, 2012.

16. Nielsen C, Ohm-Laursen L, Barington T, Husby S and Lillevang ST: Alternative splice variants of the human PD-1 gene. Cell Immunol 235: 109-116, 2005.

17. Meng Q, Yang P, Li B, Zhou H, Huang X, Zhu L, Ren Y and Kijlstra A: CD $4+\mathrm{PD}-1^{+} \mathrm{T}$ cells acting as regulatory cells during the induction of anterior chamber-associated immune deviation. Invest Ophthalmol Vis Sci 47: 4444-4452, 2006.

18. Klenerman P and Semmo N: Cellular immune responses against persistent hepatitis C virus: gone but not forgotten. Gut 55: 914-916, 2006.

19. Koziel MJ: Cellular immune responses against hepatitis $C$ virus. Clin Infect Dis 41 Suppl 1: S25-S31, 2005.

20. Magistrelli G, Jeannin P, Elson G, Gauchat JF, Nguyen TN, Bonnefoy JY and Delneste Y: Identification of three alternatively spliced variants of human CD28 mRNA. Biochem Biophys Res Commun 259: 34-37, 1999.

21. Nishimura $H$, Nose M, Hiai $H$, Minato $N$ and Honjo T: Development of lupus-like autoimmune diseases by disruption of the PD-1 gene encoding an ITIM motif-carrying immunoreceptor. Immunity 11: 141-151, 1999.

22. Greenwald RJ, Freeman GJ and Sharpe AH: The B7 family revisited. Annu Rev Immunol 23: 515-548, 2005.

23. Witsch EJ, Peiser M, Hutloff A, Buchner K, Dorner BG, Jonuleit H, Mages HW and Kroczek RA: ICOS and CD28 reversely regulate IL-10 on re-activation of human effector T cells with mature dendritic cells. Eur J Immunol 32: 2680-2686, 2002.

24. Warnatz K, Bossaller L, Salzer U, Skrabl-Baumgartner A, Schwinger W, van der Burg M, van Dongen JJ, Orlowska-Volk M, Knoth R, Durandy A, et al: Human ICOS deficiency abrogates the germinal center reaction and provides a monogenic model for common variable immunodeficiency. Blood 107: 3045-3052, 2006.

25. Nakamoto N, Cho H, Shaked A, Olthoff K, Valiga ME, Kaminski M, Gostick E, Price DA, Freeman GJ, Wherry EJ and Chang KM: Synergistic reversal of intrahepatic HCV-specific CD8 T cell exhaustion by combined PD-1/CTLA-4 blockade. PLoS Pathog 5: e1000313, 2009. 